\title{
MARX E A REALIZAÇÃo DA FILOSOFIA
}

\author{
Eide Sandra Azevêdo Abrêu
}

RESUMO: Este artigo lida com o problema da realização da filosofia no pensamento do jovem Marx, tema que remete à questão da transição Hegel-Marx. Procura mostrar que a visão de Marx da concomitante superação e realização da filosofia na revolução proletária permite pensar que a transição Hegel-Marx foi presidida por um movimento de superação e conservação simultâneas.

UNITERMOS: Realização da filosofia; relação Hegel-Marx.

Este artigo está voltado ao problema da realização da filosofia no pensamento do jovem Marx. Fazemos inicialmente um breve percurso através da "Introdução à crítica da filosofia do direito de Hegel" (Marx, s. d.), privilegiando os momentos mais importantes para a compreensão de seu desfecho: o anúncio da possível revolução proletária, na qual a filosofia seria, concomitantemente, superada e realizada.

Nesse desfecho, conforme procuraremos mostrar, é possível notar a preservação, no pensamento de Marx, do vínculo íntimo entre filosofia e revolução, que Hegel estabeleceu em suas reflexões sobre a Revolução Francesa (Hegel, s. d.). Deste modo, o tema da realização da filosofia nos conduziu ao da transição Hegel-Marx, cuja discussão procuramos encaminhar com o auxílio de Marcuse (1984) e, especialmente, de Lukács (1989). Estes autores nos ajudam a ver que o 
movimento que presidiu aquela transição não foi o da mera inversão através da qual Marx teria posto o pensamento hegeliano "de cabeça para baixo", mas sim o movimento de simultânea superação e conservação, isto é, o mesmo que Marx, no texto aqui tratado, propôs como atitude política perante a filosofia.

Em "Introdução à crítica da filosofia do direito de Hegel", como já revela o título do texto, Marx propõe a crítica da filosofia hegeliana; crítica que não deveria constituir mero exercício diletante, mas que consistiria numa forma de criticar indiretamente o direito e o Estado modernos, de que aquela filosofia seria uma expressão ideal, uma "cópia". Marx diz que irá se ocupar de uma "cópia" em razão de que a realidade alemã que tem à sua frente estaria atrasada em relação às nações européias modernas; criticá-la resultaria ainda num anacronismo. Nas palavras do autor,

“(..) A própria negação do nosso presente politico é já um fato poeirento no quarto de arrumações bistórico das nações modernas. Posso negar as perucas empoadas, mas fico ainda com perucas desempoadas. Se nego a situação alemã de 1843 dificilmente atinjo, segundo a cronologia francesa, $o$ ano de 1789, e ainda menos o centro vital do periodo atual." (Marx, s.d., p. 79)

Ao mesmo tempo que como atrasado, o status quo alemão é caracterizado como uma realidade a que a crítica deveria declarar guerra. A sociedade alemã de 1843 encontrava-se, nas palavras de Marx,

"infinitamente dividida nas mais diversas rafas, que se defrontam umas às outras com suas mesquinhas antipatias, má consciência $e$ grosseira mediocridade: e que precisamente por causa da sua situação ambigua e suspeitosa, são tratadas sem excefão, embora de maneiras 
diferentes, como existências apenas toleradas pelos senhores. $E$ vêem-se forçadas a reconhecer $e$ a admitir o fato de serem dominadas, governadas e possuídas, como uma concessão do céu! Do outro lado encontram-se os próprios governantes, cuja grandeza está em proporção inversa ao seu número!" (Marx, s. d., p. 81; grifos do autor)

Atrasada com relação aos povos modernos no tocante à situação social e política, a Alemanha emparelha-se com eles no pensamento, na filosofia. A filosofia alemã corresponderia não à realidade nacional em que brotou - uma "obra incompleta da história" -, mas sim àquela presente nas nações mais avançadas. "Conseqüentemente", diz Marx,

"ao criticarmos, em vez das oeuvres incomplètes da nossa bistória real, as oetuvres posthumes da nossa bistória ideal - a filosofia, a nossa crítica está no centro dos problemas acerca dos quais a época atual afirma: that is the question. (...)" (s. d., p. 84; grifo do autor)

Aos alemàes caberia, deste modo, criticar não apenas sua situação política real, mas especialmente sua continuação ideal na filosofia hegeliana do direito e do Estado. Mas como deveria proceder esta crítica?

Para realizar a crítica da filosofia não seria suficiente, como queria o "partido político prático", voltar "as costas à filosofia, olhando para qualquer outra parte, e murmurando umas quantas frases triviais e mal humoradas" (Marx, s. d., p. 84). Para superar a filosofia é preciso realizá-la. Esta realização da filosofia também não pode ocorrer de maneira imediata, como queriam os jovens hegelianos reunidos no “partido teórico". É preciso, segundo Marx, perceber que a filosofia é complemento ideal do mundo que a crítica quer superar e que, deste modo, a sua realização supõe sua simultânea negação.

Ao mesmo tempo em que propõe a crítica da filosofia hegeliana como complemento ideal da sociedade e do Estado modernos, Marx 
tem no seu horizonte as "tarefas práticas" a que ela induz. Deste modo, vislumbra a realização dos princípios filosóficos da racionalidade e da liberdade na revolução a ser realizada por uma classe, ainda em formação, cujas cadeias seriam radicais, que não constituiria uma classe da sociedade burguesa, mas a dissolução de todas elas; que constituiria uma classe efetivamente universal, em razão de que

"seus sofrimentos são universais e que não exige uma reparação particular porque o mal que lhe é feito não é um mal particular, mas o mal em geral, que já não possa exigir um título histórico, mas o titulo humano; de uma esfera que não se oponba a consequiências particulares, mas que se oponha totalmente aos pressupostos do sistema politico alemão; por fim, de uma esfera que não pode emancipar-se a si mesma nem emancipar-se de todas as outras esferas da sociedade sem as emancipar a todas - o que é, em suma, a perda total da bumanidade, portanto, só pode redimir-se a si mesma por uma redenção total do homem. (...)" (Marx, s. d., p. 92; grifos do autor)

O proletariado alemão seria a classe que levaria a cabo a revolução radical, a revolução que emanciparia a humanidade, que superaria a filosofia enquanto complemento ideal do mundo e que, ao mesmo tempo, realizaria os princípios filosóficos da racionalidade e da liberdade, no "dia da ressurreição da Alemanha com o cantar do galo das Gálias” (Marx, s. d., p. 93).

\section{II}

No movimento de superação e realização simultâneas da filosofia, enxergado por Marx na revolução proletária, podemos perceber a recuperação de um vínculo que já havia sido estabelecido por Hegel, qual seja, o vínculo entre filosofia e revolução, presente de uma maneira bastante forte na interpretação hegeliana da Revolução Francesa como 
momento histórico de busca de edificação do mundo conforme a razão. $\mathrm{Na}$ seguinte passagem, que consiste numa belíssima exaltaçào da Revolução Francesa, fica nítida uma visão desse momento do processo histórico universal como momento em que o homem, apoiado em sua própria razão, dirige-se contra a realidade com que se defronta, buscando construi-la em conformidade com ela:

(...) Desde que o sol está no firmamento e os planetas giram em torno dele, não se havia visto que o bomem se apoiasse sobre sua própria cabega, isto $\dot{e}$, sobre o pensamento, e edificasse a realidade conforme $o$ pensamento. Anaxagoras foi o primeiro a dizer que o pensamento rege o mundo; agora pela primeira vez o bomem chegou a reconbecer que o pensamento deve reger a realidade espiritual. Foi isto, por conseguinte, um magnifico alvorecer. Todos os seres pensantes celebraram esta época. Uma emoção sublime reinava naquele tempo; 0 entusiasmo do espirito estremeceu o mundo, como se só então se bouvesse chegado à efetiva reconciliaģào do divino com o mundo." (Hegel, s. d., p. 400)

Acreditamos que resida aqui, no estreito vínculo entre filosofia e revolução, uma das "tendências críticas da filosofia hegeliana" que teriam sido, segundo Marcuse (1984), incorporadas pela "teoria social marxista". Ao identificar "a ordem política e social efetuada pelos homens com a base sobre que se devia realizar a razão", Hegel teria, segundo Marcuse, trazido "a filosofia ao limiar da negação da filosofia, constituindo por isso o tínico elo entre as formas vellsa e nova da teoria crítica, entre a filosofia e a teoria social"'(1984, p. 232).

Antes de Marcuse, Lukács havia chamado a atenção para o profundo vínculo existente entre Marx e Hegel no tocante à relação entre filosofia e história (Lukács, 1989, p. 31). Entretanto, neste vínculo não deve ser reconhecida apenas, segundo Lukács, uma continuidade, pois 
"justamente aqui, onde o profundo parentesco do materialismo bistórico com a filosofia de Hegel surge, no problema da realidade (...), é necessário, mesmo em poucas palavras, chamar a atenção sobre a não menos decisiva linha de ruptura que os separa. Esta linba de ruptura encontra-se igualmente no nivel da realidade, do problema da unidade do processo bistórico. (...)" (1989, p. 31; grifo do autor)

Apesar de Hegel ter vinculado filosofia e realidade, pensamento e história, esta termina por só existir, segundo as palavras de Marx, citado por Lukács, "na consciência, na opinião e na representação dos filósofos, na imaginação especulativa” (1989, p. 32). Ainda segundo Marx, citado por Lukács,

'Já em Hegel o espirito absoluto da bistória busca a sua matéria nas massas mas só na filosofia encontra a sua expressão adequada. $O$ filósofo aparece como órgão pelo qual o espirito absoluto que faz a bistória se eleva na consciência após o decurso, depois. A participação do filósofo na bistória reduz-se a esta consciência ulterior, porgue o espirito absoluto realiza inconscientemente o movimento real. $O$ filosofo chega, pois, post festum. (...)"(1989, p. 31)

Existiriam, assim, "tendências contraditórias" no pensamento hegeliano, que "não puderam atingir uma clarificação", em razão de limites históricos. Segundo Lukács, "Hegel não conseguitu chegar às forfas verdadeiramente motrizes da bistória, porque, na época em que nascen o seu sistema, essas forfas não eram ainda suficientemente visiveis (...)". (1989, p. 33)

Marx, por contar com o advento histórico do proletariado, a partir de cujo ponto de vista seria possível desvendar o todo social, teria podido apanhar e levar "às últimas conseqüências, com uma lógica sem concessões, a tendência histórica que se encontra na filosofia hegeliana", dela eliminando os "vestígios mitologizantes" (Lukács, 1989, p. 32). Esses "vestigios" 
"situam-se no nivel da filosofia da reflexão que Hegel combateu com violência e acrimônia durante toda a vida e contra o qual empregou todo o seu método filosófico, o processo e a realidade concreta, a dialética e a bistória. A critica marxiana de Hegel é, pois, o seguimento e a continuação diretos da critica que o próprio Hegel exerceu contra Kant e Fichte."(Lukács, 1989, p. 32)

Conforme podemos ver, na exposição lukacsiana Marx se constitui no legítimo herdeiro da filosofia hegeliana ao realizar o mesmo movimento que, em "Introdução à crítica da filosofia do direito de Hegel", propõe como atitude com relação à filosofia: a concomitante conservação e superação. Com isto, pôde enxergar, no futuro, a superação da filosofia enquanto complemento ideal do mundo, e a simultânea realização dos princípios filosóficos da razão e da liberdade na revolução radical levada a cabo pelo proletariado.

ABSTRACT: This article deals with the problem of philosophy's realization in early Marx's thought, a theme which sends us to the question of Hegel-Marx transition. It aims to show that Marx's view of concomitant abolition and realization of philosophy in proletarian revolution allows one to think that Hegel-Marx transition took place through a movement in which surmounting and conservation happen at the same time.

KEYwORDS: realization of philosophy; Hegel-Marx transition

\section{REFERÊNCIAS BIBLIOGRÁFICAS}

HEGEL, G. W. F. "La revolución francesa y sus consecuencias". In: Filosofia de la História Universal. Buenos Aires, s. d., pp. 395-411. 
LUKÁCS, Georg. "O que é o marxismo ortodoxo?" In: História e Consciencia de Classe: estudos de dialéctica marxista. Trad. de Telma Costa; revisão de M. A. Resende e C. Costa. 2a ed. Rio de Janeiro: Elfos Ed.; Porto: Publicações Escorpião, 1989. pp. 15-40.

MARCUSE, Herbert. "Da filosofia à teoria social". In: Razão e Revolução: Hegel e o advento da teoria social. Trad. de Marília Barroso. 3a ed. Rio de Janeiro: Paz e Terra, 1984. pp. 231-237.

MARX, Karl. "Contribuição à crítica da filosofia do direito de Hegel". In: Manuscritos Econômico-Filosóficos. Trad. de Artur Morão. Lisboa: Edições 70. s. d., pp. 75-93. 